\title{
基于扎根理论的社区参与国家公园建设与管理的机制 研究
}

\author{
何思源 ${ }^{1, *}$ ，魏 钰 $^{2}$, 苏 杨 $^{3}$, 闵庆文 ${ }^{1,4}$ \\ 1 中国科学院地理科学与资源研究所, 北京 100101 \\ 2 中国科学院科技战略咨询研究院, 北京 100190 \\ 3 国务院发展研究中心《管理世界》杂志社,北京 100013 \\ 4 中国科学院大学,北京 100049
}

\begin{abstract}
摘要:大量研究表明自然保护地周边社区居民对保护地的态度是影响社区参与保护,实现保护地管理目标的主要因素, 由此建 立了“认知-态度-参与” 的行为逻辑。中国国家公园体制建设希望进一步推进社区与保护地的关系,全面提升自然保护管理效 率, 也建立在对这一行为逻辑的认同之上。为验证社区认知与行为的关系,并为促进不同利益相关者参与国家公园建设与管理 提供科学支持,研究试图分析武夷山国家公园体制试点区社区居民的国家公园的“认知-态度-参与” 的行为逻辑以揭示社区参 与国家公园建设与管理的深层机制。与一般研究不同在于,本研究是针对正在建设中的国家公园,使得本地利益相关方的态度 有机会影响国家公园建设进程。为获得社区 “认知-态度-参与”核心观念, 探索社区参与的过程和方式,提出促进社区参与的方 法, 研究采用扎根理论这一质性研究方法, 基于对本地利益相关者采用半结构化开放问题的深度访谈,归纳出概念与范畴,形成 社区参与国家公园建设与管理的理论。研究首先形成 45 个概念与 13 个范畴,通过范式模型研究发现, 稳定资源使用权利、引 导社区参与决策、保障社区发展权利、创新社区产业模式、提高个体适应能力、降低政策风险影响等六个主范畴能够解释社区居 民对国家公园的认知-态度-参与这一行为逻辑。通过归纳主范畴,研究进一步提炼出社区参与国家公园建设与管理的理论核 心在于社区自然资源管理的自主性、创新性与适应性,其内在机制在于社区参与是一个自主性提高的动态过程,需要通过保障 社区生计资源禀赋来实现长期的价值转化,最终使其成为社会-生态系统适应性治理的组成部分。在理论阐释基础上,研究提 出从改善社区认知、提升社区参与角度推进国家公园建设的路径。研究也指出,所提出的社区参与机制理论能够提炼量化指标 评价社区参与,追踪武夷山国家公园体制试点进程。
\end{abstract}

关键词:态度;社区参与;国家公园;扎根理论;自然保护地管理;自然资源管理

\section{A grounded theory approach to understanding the mechanism of community participation in national park establishment and management}

\author{
HE Siyuan ${ }^{1, *}$, WEI Yu ${ }^{2}$, SU Yang ${ }^{3}$, MIN Qingwen ${ }^{1,4}$ \\ 1 Institute of Geographic Sciences and Natural Resources Research, Chinese Academy of Sciences, Beijing, 100101, China \\ 2 Institutes of Science and Development, Chinese Academy of Sciences, Beijing, 100190, China \\ 3 Management World, Development Research Center of the State Council, Beijing, 100013, China \\ 4 University of Chinese Academy of Sciences, Beijing, 100049, China
}

\begin{abstract}
Evidence abounds that attitude of local stakeholders towards the protected area influences community participation to conservation, thus affects the achievement of conservation targets, as tested in the "perception-attitude-
\end{abstract}

基金项目:国家自然科学基金项目 (42001194); 北大-林肯研究基金项目(FS07-20201101-HSY)

收稿日期: 2020-04-02; 网络出版日期:2021-02-24

* 通讯作者 Corresponding author.E-mail: hesy@ igsnrr.ac.cn 
participation” hypothesis. Perception provides an important means of assessing the people-park relations which reflects the performance of the on-going China national park building. Exploring perceptions in different facets of national park establishment and management can help identify aspects of current progresses in the national park pilot that are promising for improvement of management efficiency and those that need innovation. Taking Wuyishan as a case, this study identifies and analyses perception of, attitude to, and community participation into the national park pilot of local residents to analyse the mechanism affecting participation based on the "perception-attitude-participation" hypothesis, and to help facilitate local communities into national park construction and management. The basic hypothesis is that participation as a behaviour is directed by the positive or negative attitude towards national park, which is formed by a judgement of combination of perceptions to different aspects. Contrary to similar studies, the study is carried out on the case of the park in establishment, where the attitudes of local stakeholders have a chance to influence the process of the national park establishment. The qualitative method of the grounded theory is used to inductively identify key concepts concerning perception, attitude and participation, and develop a community participation theory from in-depth, semi-structured, and open-ended interviews with local stakeholders. The open coding identified 45 concepts and 13 categories, and paradigm analysis revealed six categories which testify the perception-attitude-participation hypothesis, those including stabilising resource use right, facilitating community participation in decision-making, ensuring development right, innovating industrial modes, improving individual adaptability and reducing policy risks. The finally induced mechanism of community participation in the national park establishment and management is reasoned by the autonomy, innovation and adaptability of natural resource management. A more comprehensive description of the reasons and the background of their formation is provided that community participation is a dynamic process of improving autonomy, during which the livelihood resource endowment should be guaranteed to achieve long-term valorisation, and is finally assimilated to a part of social-ecological system adaptive governance. Based on the theoretical explanation, the article put forwards ways of improving community perception and promoting participation. Finally, this theory can be further extracted to quantitative indicators to evaluate community participation progress in tracking the national park establishment and operation.

Key Words: attitude; community participation; national park; grounded theory; protected area management; natural resource management

自然保护地-社区关系研究指出, 居民对自然保护的认知影响他们对于建立自然保护地的态度,积极的态 度能够促进社区参与保护地管理 ${ }^{[1-3]}$, 从而减少冲突, 改善自然保护地管理成效 ${ }^{[4]}$ 。因此, 从认知角度分析自 然保护地-社区关系, 对 “认知-态度-参与”这一行为逻辑进行验证, 能够为管理决策提供指导, 为管理成效评 估提供基线数据 ${ }^{[5]}$ 。

国际上对当地社区对保护地的认知-态度-参与的研究已在北美、亚洲、非洲、欧洲等地开展了 30 余年。 研究发现, 除人口统计与社会-经济因素外, 态度主要受到社区对保护地带来的成本-收益认知的影响 ${ }^{[6]}$, 自然 保护地发展历史、管理水平、社区参与程度等也是重要因素 ${ }^{[7-9]}$; 总体而言,社区对自然保护地的正面态度可 以带来有利于保护的行为 ${ }^{[1]}$, 而社区参与主要受到对保护地建立本身、管理者工作、管理成效的认可态 度 ${ }^{[3,10-11]}$ 的直接影响, 以及诸多影响态度的因素, 如教育水平、经济收益、保护意识等的间接影响 ${ }^{[12]}$ 。

国内相关研究在近 20 年开展较多, 以自然保护区-社区关系研究为主, 通过运用认知、态度与行为量表, 以描述统计 ${ }^{[13-17]}$ 、相关分析 ${ }^{[18-19]}$ 、方差分析 ${ }^{[20]}$ 、回归分析 ${ }^{[21-22]}$ 、因子分析 ${ }^{[23]}$ 等方法, 探索影响认知、态度与行 为的关键因素, 检验认知-态度-行为假设 ${ }^{[17,20]}$ 。研究发现, 教育水平与收人是最为普遍的影响社区对保护地 认知与态度的人口社会经济因素 ${ }^{[13-14,20,22,24-25]}$, 性别因素逐渐得到重视 ${ }^{[22-26]}$; 与国外研究结果类似, 成本-收益

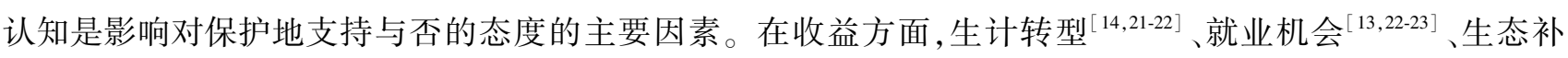
偿 ${ }^{[21-22,27]}$ 等个人与家庭经济发展和生活水平提高, 道路与基础设施建设 ${ }^{[14,19,23]}$ 、社会福利发展与保护成效等 


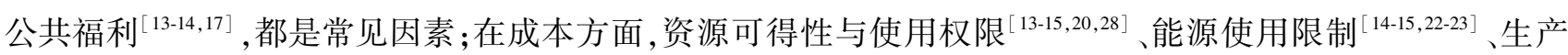
经营限制 ${ }^{[20-21,23]}$ 等生计影响因素比较普遍, 人兽冲突也被频繁提及 ${ }^{[13-14,17,20-21,23]}$ 。此外, 文化因素 ${ }^{[23]}$ 、收益与 补偿公平性 ${ }^{[27,29]}$ 、保护地管理水平 ${ }^{[17,22-23]}$ 、社区参与程度 ${ }^{[16,22,24]}$ 也会影响社区对保护地的态度。同样,国内 研究也发现对保护地的管理认可态度影响社区参与意愿 ${ }^{[17,23]}$ 。

上述国内外从认知角度进行的自然保护地-社区关系研究主要存在以下问题: 1) 指标体系缺乏系统性和 理论依据, 对于认知、态度、(参与) 行为等概念及其相互关系没有明确定义和可验证的假设;2) 预设的价值判 断条款无法穷尽,往往按照保护地既定管理目标和建立或申报文件要求设计 ${ }^{[22,30-31]}$; 3) 研究缺乏对影响因素 间关系及其作用机制的系统性分析。为解决上述问题，国内外研究者一方面对从社会心理角度强化理论基 础 ${ }^{[3,5,19,23,31]}$, 另一方面尝试采用扎根理论方法, 在没有预设影响因素的前提下从社区访谈材料中进行归纳式 分析, 让社区对自然保护地的认知、态度、行为的关系自然浮现并分析内在逻辑 ${ }^{[34-35]}$ 。不过, 我国学者利用扎 根理论对自然保护地-社区关系研究鲜有开展,仅有部分遗产管理研究涉及社区视角的生计公平、生计发展、 文化认同、社区营造模式、生态补偿机制等 ${ }^{[36-40]}$ 。

自 20 世纪 80 年代以来,我国在自然保护领域采用了一系列协调机制改善自然保护区-社区关系,如基于 社区的自然资源管理, 社区共管等方式, 但存在受益群体小, 缺乏长效机制等问题 ${ }^{[13]}$ 。当前我国国家公园体 制正在建设中,如何让当地社区居民认可、支持并参与国家公园建立和管理是一个关键问题。对此,研究者采 用预设指标体系, 发现国家公园的教育价值与利用价值影响社区支持建设神农架国家公园 ${ }^{[41]}$; 通过描述性研

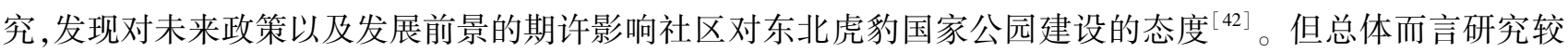
少, 尚未探讨社区参与国家公园建设与管理的内在机制。

因此, 本研究试图在 “认知-态度-参与” 的行为逻辑下, 解析国家公园周边社区参与国家公园建设与管理 过程与方式, 即参与机制。本研究的主要目标是分析武夷山国家公园体制试点邻近社区参与国家公园建设与 管理的认知-态度-参与核心观念,探索其相互关系与作用方式,并在所揭示的社区参与机制基础上进一步提 出促进社区参与的可能方式。为达到研究目标, 研究采用扎根理论方法, 以深度访谈方式调查社区居民对武 夷山国家公园的认知, 对建立武夷山国家公园的态度以及对参与建设与管理的观点获得原始数据, 依照扎根 理论分析流程, 以开放编码识别出 “认知-态度-参与” 这一行为逻辑中的关键概念; 以主轴编码的范式模型分 析为主要手段形成关键概念的逻辑关系,继而以选择性编码形成依据社区参与国家公园建设与管理机制模 型, 并依托相关理论与以往研究阐释模型所蕴含的国家公园社区协同发展路径; 在此基础上为国家公园的社 区参与提供实施路径。

\section{1 方法}

\section{1 理论方法}

根据研究目的,本文旨在探索国家公园体制建设中社区参与的动机与可能途径。研究问题设计主要基于 态度理论 ${ }^{[43]}$, 态度是对事物的正面或负面评价, 由信念构成, 而信念是人们在研究对象与其属性间建立的联 系,一系列的信念被称为认知; 积极的态度是积极行动的一个可信的预测。因此, 研究界定认知是指社区居民 对国家公园建设情况和问题的认识; 态度是对建立国家公园是否认可,参与是社区居民直接或间接进行国家 公园建设与管理的能力和行动 ${ }^{[10]}$ 。研究使用扎根理论方法, 通过不断进行数据比较来归纳形成理论。扎根 理论是重要的质性研究方法, 在没有先验性假设和结论的情况下, 自下而上地以开放性心态收集资料, 寻找反 映所关注问题的核心概念, 是以归纳和演绎、定性与定量结合的归纳性研究方法 ${ }^{[44]}$ 。研究遵循扎根理论分析 路径, 在确定深度访谈主题与进行调研后, 对数据进行编码 ${ }^{[45]}$ 。编码步骤为三步: (1)开放性编码, 从原始访谈 资料中逐节篮选并识别对于武夷山国家公园认知的显著陈述, 形成概念并将类似概念归纳为范畴; 这些范畴 主要由实证数据和研究问题来定义。(2)主轴编码, 分析范畴之间的关系, 归纳出主范畴和副范畴, 并采用范式 模型建立范畴关联。(3)选择性编码, 选择核心范畴, 将其与其他范畴系统相关联并阐述其关系, 再次篮选访谈 
数据, 对概念化尚未完备的范畴进行补充。最终, 将各 范畴作为社区参与国家公园建设的影响因子,得到社区 认知视角下参与国家公园建设和管理的理论模型。文 献探讨是扎根理论应用的重要环节, 因此, 在理论构建 后, 研究与现有理论进行比较与融合, 提出国家公园社 区协同发展路径,丰富扎根理论的成果(图 1)。

\section{2 数据获取}

武夷山国家公园体制试点区总面积为 1001.41 $\mathrm{km}^{2}$, 涉及武夷山、建阳、光泽、邵武等 4 个县 (市、区) 9 个乡镇(街道), 29 个行政村,范围内有人口 3352 人, 周边 $2 \mathrm{~km}$ (福建省境内) 涉及上述 4 个县 (市、区) 周边 的 12 个乡镇 (街道), 20 个行政村, 涉及人口近 4 万。 武夷山国家公园所涉及社区的经济收人以茶叶、毛竹、

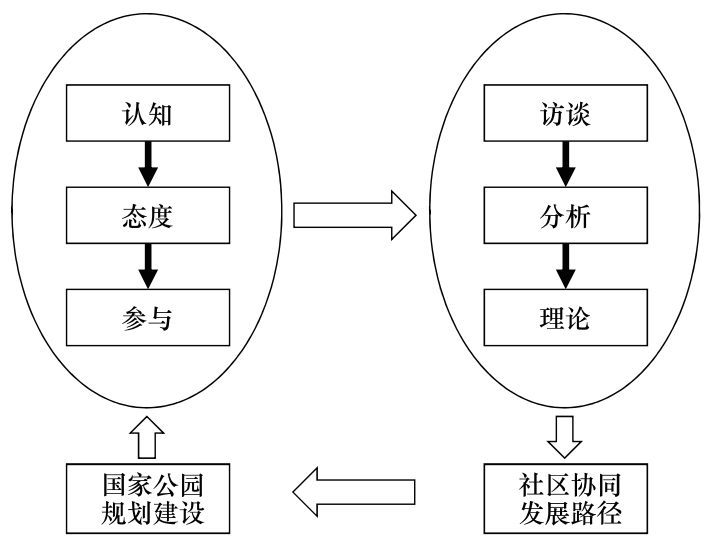

图 1 研究理论基础和研究思路

Fig.1 Study theoretical base and framework 旅游、外出务工和其他经济产业为主, 收人结构同质性强, $80 \%$ 以上的社区以茶叶生产为主, 毛竹次之。武夷 山国家公园体制试点区建立在原有国家级自然保护区、风景名胜区等自然保护地空间整合与管理统一的基础 上, 主要保护同纬度最大和最具代表性的亚热带常绿阔叶林。社区居民对自然保护历史沿革与制度变化有一 定的认知 ${ }^{[46]}$ 。

调研采用深度访谈方法,于 2016 年 7 月 18 日至 26 日在武夷山国家公园体制试点区规划范围内及其外 围乡镇(武夷山市范围内), 以一对一形式进行人户调查。受访户的选择主要使用理论抽样方法 ${ }^{[38]}$, 根据行 政村人口与产业数据确定具体行政村,由行政村村委引荐产业代表家庭,确保受访人的空间分布均匀、代表性 产业均被囊括, 有助于最大化地在属性维度上形成概念, 寻找概念间的关系; 由产业代表性家庭的受访人继续 滚雪球似的推荐, 每户仅访谈一人 ${ }^{[25]}$ 。在进行访谈的同时继续提出、分析问题并在后续访谈中提出相关问 题,通过对不同代表性产业家庭、距离国家公园边界不同远近的农户进行访谈来不断丰富资料。访谈过程中, 在被访谈者知情并允许的情况下使用录音笔记录供转录编码, 对不同意被录音的受访者书面记录主要内容。 访谈均为匿名化,不记录与研究无关的隐私信息。

调研所依托的项目对 300 余户主要居住在原自然保护区、风景名胜区及九曲溪上游地带的农户进行了访 谈, 包括结构化与半结构化问题 ${ }^{[46,59]}$ 。涉及本研究的深度访谈以半结构化开放问题进行, 这种方式下受访者 自行掌控回答的内容和结构, 研究者能够最大限度地获得对问题的新见解 ${ }^{[30]}$ 。受访者主要被问及如何看待 建立武夷山国家公园一事, 其他问题依据访谈情况而适时调整,这样受访者可以自由表达他们对武夷山国家 公园的看法, 它的建设情况, 保护管理, 自己在其中的角色等。大部分受访者都乐于谈论国家公园并直接表达 对武夷山国家公园建设的态度。多数人谈及对建设过程的不了解或见解被忽视; 大部分人都会提出建立国家 公园会带来的具体限制和不便。根据信息相似程度和提供内容的丰富程度,研究最终取得 264 位受访者的一 手资料。编码过程在 Nvivo12 软件中进行。

\section{2 范式提炼和模型构建}

\section{1 开放编码}

对访谈记录占标签, 对类似标签进行概念化合并,在概念基础上发现范畴。经过逐词、逐句、逐段编码, 反 复分析, 增删修改概念 , 最终得到可以反映社区对国家公园的认知、态度与参与的 13 个范畴 (表 1)。

\section{2 主轴编码}

采用范式模型, 梳理开放编码中提取的“认知-态度-参与” 的 13 个范畴, 将其以研究的核心现象为中心, 根据 13 个范畴与核心现象间的关系划分为相关条件、应对策略和结果 ${ }^{[47]}$ (图 2); 进一步将划分后的条件-应 
对策略与结果的逻辑路径整合为主范畴,从而呈现关键概念之间的逻辑关系 (表 2)。

\section{表 1 开放编码形成的概念和范畴}

Table 1 Concept and category of open coding

\begin{tabular}{|c|c|c|c|}
\hline 编号 & $\begin{array}{l}\text { 范畴 } \\
\text { Category }\end{array}$ & $\begin{array}{l}\text { 概念 } \\
\text { Concept }\end{array}$ & $\begin{array}{l}\text { 范畴语句占比 } / \% \\
\text { Proportion of category }\end{array}$ \\
\hline 1 & 产业多元化 (49) & $\begin{array}{l}\text { 参与基建 (1) 生态产业发展 (3) 高附加值产业 (3) 生态旅游转型 } \\
\text { (36) 特色产业 (3) 文化推广 (3) }\end{array}$ & 16.78 \\
\hline 2 & 个人能力 (11) & 个人能力不足 (2) 量力而行 (7) 年龄限制 (2) & 3.77 \\
\hline 3 & 共同治理(19) & $\begin{array}{l}\text { 监督国家公园建设 (1) 参与生态保护 (10) 管理权 (1) 资源不能垄断 } \\
\text { (1) 自己确保资源生态良好 (3) 个人做好地方表率 (3) }\end{array}$ & 6.51 \\
\hline 4 & 国家公园管理体制 (31) & 管理单位理顺 (1) 管理人员负责 (2)认可国家公园建设 (28) & 10.62 \\
\hline 5 & 国家公园理念 (25) & 不够了解建设进展 (21) 开展生态教育 (2) 宣传国家公园效益 (2) & 8.56 \\
\hline 6 & 福利多样化(29) & 经济效益(9)个人发展机遇 (11) 生态效益 (2) 社会整体福利 (7) & 9.93 \\
\hline 7 & 利益冲突 ( 8) & 不能影响生活便利 (2)不要影响生产 (5) 政策不公平 (1) & 2.74 \\
\hline 8 & 路径依赖 (13) & 继续从事现有产业 (13) & 4.45 \\
\hline 9 & 缺乏决策参与机制 ( 66) & 服从命令 (45) 没有社区参与意识 (21) & 22.60 \\
\hline 10 & 社区赋权 (10) & 基于交流形成政策 (4) 自主参与经营 (4) 合作经营形成品牌 (2) & 3.42 \\
\hline 11 & 土地权属 ( 8) & 土地政策稳定 (1) 林地自主管理权 (3) 自然资源投资人股 (4) & 2.74 \\
\hline 12 & 微观政策支持( 14) & 产业发展引导 (4)生态移民配套( 7)生态补偿(3) & 4.79 \\
\hline 13 & 政策风险(9) & 国家公园建设有风险 (5) 不信任实施者 (2) 政策执行力低 (2) & 3.08 \\
\hline
\end{tabular}

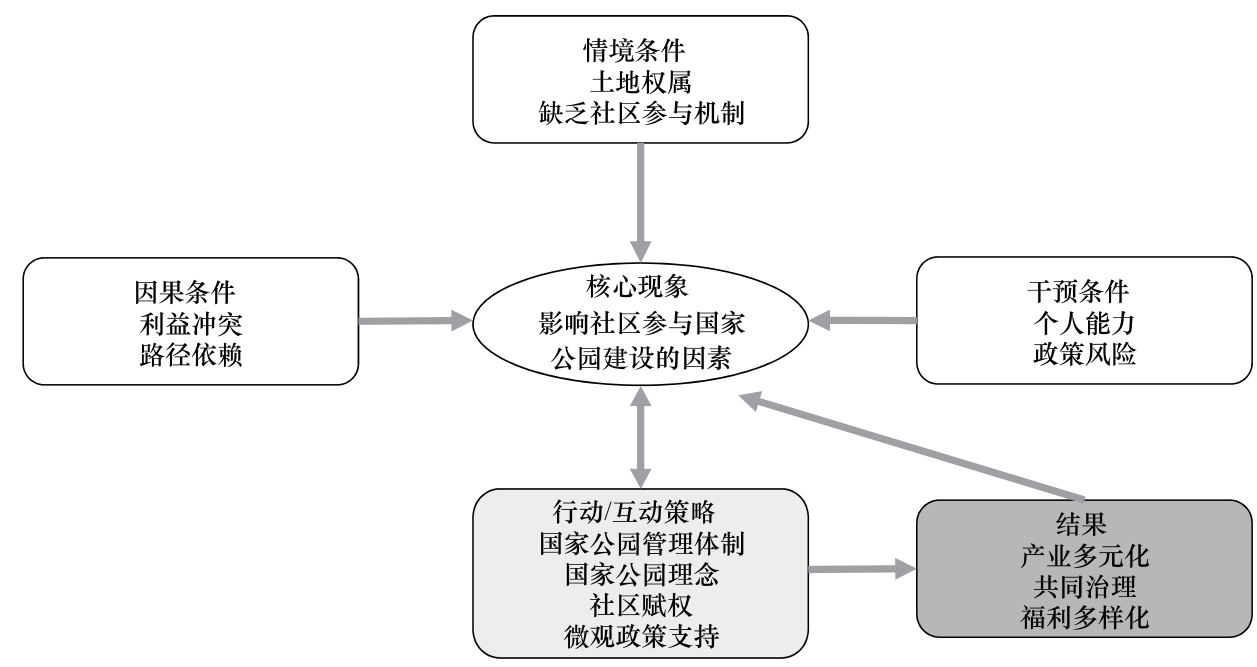

图 2 社区参与国家公园建设的相关因素的范式模型 [48]

Fig.2 Paradigm model of community participation in National Park designation process

现象是数据所指的中心思想或事件, 以及参与者通过一系列互动策略所管理的内容。根据研究目的, 本 研究的核心现象是武夷山社区居民参与国家公园建设; 情境条件指影响所关注现象的背景条件,在本研究中, 影响武夷山社区居民参与国家公园建设的背景条件包括社区对土地权属的要求和一直以来决策参与机制的 缺乏。干预条件是指在特定情境或背景下,通过影响交互策略而影响所研究现象的一般条件, 比情境条件更为 直接的影响互动策略, 这里包括社区居民的个人能力和所感知的政策风险。因果条件指导致现象发生的更为直 接的事件,这里包括国家公园中社区与国家公园建设产生的利益冲突与产业路径依赖。行动/互动策略用于管 理和响应研究现象, 社区居民识别的策略包括国家公园管理体制, 社区赋权,微观政策支持与国家公园理念。结 果是对研究现象实施策略后的成果,具有不可预测性,在研究中包括产业多元化、共同治理与福利多样化。 
主轴编码最终将 13 个范畴根据范式模型归纳为 6 个主范畴, 每个主范畴由一条逻辑轴线构成。例如,社 区认为在土地权属稳定下进行资源管理影响他们认识和参与国家公园建设 (现象发生的情境), 这就需要微 观政策有利于维持土地资源的合理利用,促进社区利用土地资源开展合理经营(对该情境实施的管理行动或 方案), 通过保障土地利用合法权益为社区带来多元化的福利和自主、公平的资源利用行为(行动的结果), 这 一组范畴间的关系整合纳人同一主范畴——“稳定资源使用权利”。

表 2 主轴编码结果

Table 2 Category and subcategory from axial coding

\begin{tabular}{|c|c|c|c|}
\hline \multirow{2}{*}{$\begin{array}{l}\text { 主范畴 } \\
\text { Category }\end{array}$} & \multicolumn{3}{|c|}{$\begin{array}{c}\text { 副范畴及部分概念 } \\
\text { Sub-category and some concepts }\end{array}$} \\
\hline & $\begin{array}{c}\text { 条件 } \\
\text { Conditions }\end{array}$ & $\begin{array}{l}\text { 行动/互动策略 } \\
\text { Action/Interaction strategies }\end{array}$ & $\begin{array}{l}\text { 结果 } \\
\text { Consequences }\end{array}$ \\
\hline $\begin{array}{l}\text { 稳定资源使用权利 } \\
\text { Stabilising resource use right }\end{array}$ & 土地权属 & $\begin{array}{l}\text { 微观政策支持、自主参与经营、 } \\
\text { 合作经营形成品牌 }\end{array}$ & $\begin{array}{l}\text { 福利多样化、资源不能垄断、自己 } \\
\text { 确保资源生态良好 }\end{array}$ \\
\hline $\begin{array}{l}\text { 引导社区参与决策 } \\
\text { Guiding the community to participate in } \\
\text { decision-making }\end{array}$ & $\begin{array}{l}\text { 缺乏社区 } \\
\text { 参与机制 }\end{array}$ & 社区赋权、管理单位理顺 & 共同治理 \\
\hline $\begin{array}{l}\text { 保障社区发展权利 } \\
\text { Ensuring community development right }\end{array}$ & 利益冲突 & $\begin{array}{l}\text { 社区赋权、生态移民配套、生态 } \\
\text { 补偿、开展生态教育 }\end{array}$ & 共同治理、福利多样化 \\
\hline $\begin{array}{l}\text { 创新社区产业模式 } \\
\text { Innovating community industrial modes }\end{array}$ & 路径依赖 & 国家公园理念、产业发展引导 & 产业多元化 \\
\hline $\begin{array}{l}\text { 提高个体适应能力 } \\
\text { Improving individual adaptability }\end{array}$ & 个人能力 & $\begin{array}{l}\text { 微观政策支持、宣传国家公园 } \\
\text { 效益 }\end{array}$ & 产业多元化、社会整体福利 \\
\hline $\begin{array}{l}\text { 降低政策风险影响 } \\
\text { Reducing policy risk impacts }\end{array}$ & 政策风险 & $\begin{array}{l}\text { 国家公园管理体制、基于交流形 } \\
\text { 成政策、国家公园理念 }\end{array}$ & 共同治理、福利多样化 \\
\hline
\end{tabular}

\section{3 选择性编码}

选择性编码进一步从主范畴确定的条件-应对策略与结果路径提取核心范畴,将其与其他范畴系统联系 并阐释其相互关系, 对概念化尚未完备的范畴进行补充, 从而形成一个完备的社区参与国家公园建设与管理 的条件-应对策略-结果路径 (表 3), 并通过回溯“认知-态度-参与” 的关键概念与逻辑关系生成社区参与国家 公园建设与管理机制模型 (图 3)。

将 13 个范畴和 6 个主范畴与自然资源管理和保护地治理相关理论进行比较,通过再次梳理主轴编码形 成的范式模型, 将社区参与与发展权利纳人 “提高社区权力”, 将个体适应能力与政策风险影响纳人 “增强适 应能力”, 将其余两个主范畴进行转述与前述两个核心范畴匹配。将从原始数据中提炼的核心范畴与主范 畴、范畴之间的关系重新置于原始资料中进行检验, 没有发现新概念, 主范畴之间的关系已经饱和。将范式模 型揭示的研究问题及其逻辑提炼为 “提高社区自然资源管理的自主性、创新性与适应性,实现社区参与国家 公园建设与管理的国家公园社区共治共享”, 并以范式模型分析核心范畴与其他范畴的关系 (表 3)。通过呈 现原始资料的编译过程,研究得到反映武夷山国家公园体制建设中社区基于对国家公园的认知、对其建设的 态度而得到的参与国家公园建设和管理的理论模型(图 3)。

\section{3 研究发现及机理分析}

研究运用扎根理论方法,发现了武夷山国家公园周边社区对其建立与管理的认知、态度与参与的核心观 念及其相互关系, 并以此构建了社区参与国家公园建设与管理的理论模型。然而, 从实现研究目的来看, 扎根 理论方法不仅在于发现可能的机制, 更重要的是通过所获得的理论来分析社区参与现状和问题,对理论可信 度进行说明。因此, 基于扎根理论提出的社区参与机制, 通过文献资料和理论对比, 研究从四个方面阐释社区 参与的内在机理。 
表 3 核心范畴形成及其范式模型表达

Table 3 Key Category and the paradigm model expression

\begin{tabular}{|c|c|c|c|c|}
\hline \multirow[b]{2}{*}{$\begin{array}{l}\text { 主范畴 } \\
\text { Category }\end{array}$} & \multirow[b]{2}{*}{$\begin{array}{l}\text { 核心范畴 } \\
\text { Key category }\end{array}$} & \multicolumn{3}{|c|}{ 核心范畴范式模型 } \\
\hline & & $\begin{array}{c}\text { 条件 } \\
\text { Conditions }\end{array}$ & $\begin{array}{l}\text { 行动/互动策略 } \\
\text { Action/Interaction } \\
\text { strategies }\end{array}$ & $\begin{array}{l}\text { 结果 } \\
\text { Consequences }\end{array}$ \\
\hline $\begin{array}{l}\text { 引导社区参与决策 ——参与机制 } \\
\text { Guiding the community to participate in decision- } \\
\text { making: participation mechanism }\end{array}$ & 提高社区权力 & 自主性 & $\begin{array}{l}\text { 宏观管理体制协同微观 } \\
\text { 经济政策调和公私利益 }\end{array}$ & $\begin{array}{l}\text { 社区参与并受益 } \\
\text { 于国家公园建设 }\end{array}$ \\
\hline $\begin{array}{l}\text { 保障社区发展权利——调节机制 } \\
\text { Ensuring community development right: } \\
\text { regulating mechanism }\end{array}$ & & & & \\
\hline $\begin{array}{l}\text { 稳定资源使用权利 ——保障机制 } \\
\text { Stabilising resource use right: } \\
\text { safeguard mechanism }\end{array}$ & 保障资源禀赋 & 创新性 & & \\
\hline $\begin{array}{l}\text { 创新社区产业模式——创新机制 } \\
\text { Innovating community industrial modes: } \\
\text { innovation mechanism }\end{array}$ & 优化资源利用 & & & \\
\hline $\begin{array}{l}\text { 提高个体适应能力——应对机制 } \\
\text { Improving individual adaptability: } \\
\text { response mechanism }\end{array}$ & 增强适应能力 & 适应性 & & \\
\hline $\begin{array}{l}\text { 降低政策风险影响——管理机制 } \\
\text { Reducing policy risk impacts : } \\
\text { management mechanism }\end{array}$ & & & & \\
\hline
\end{tabular}

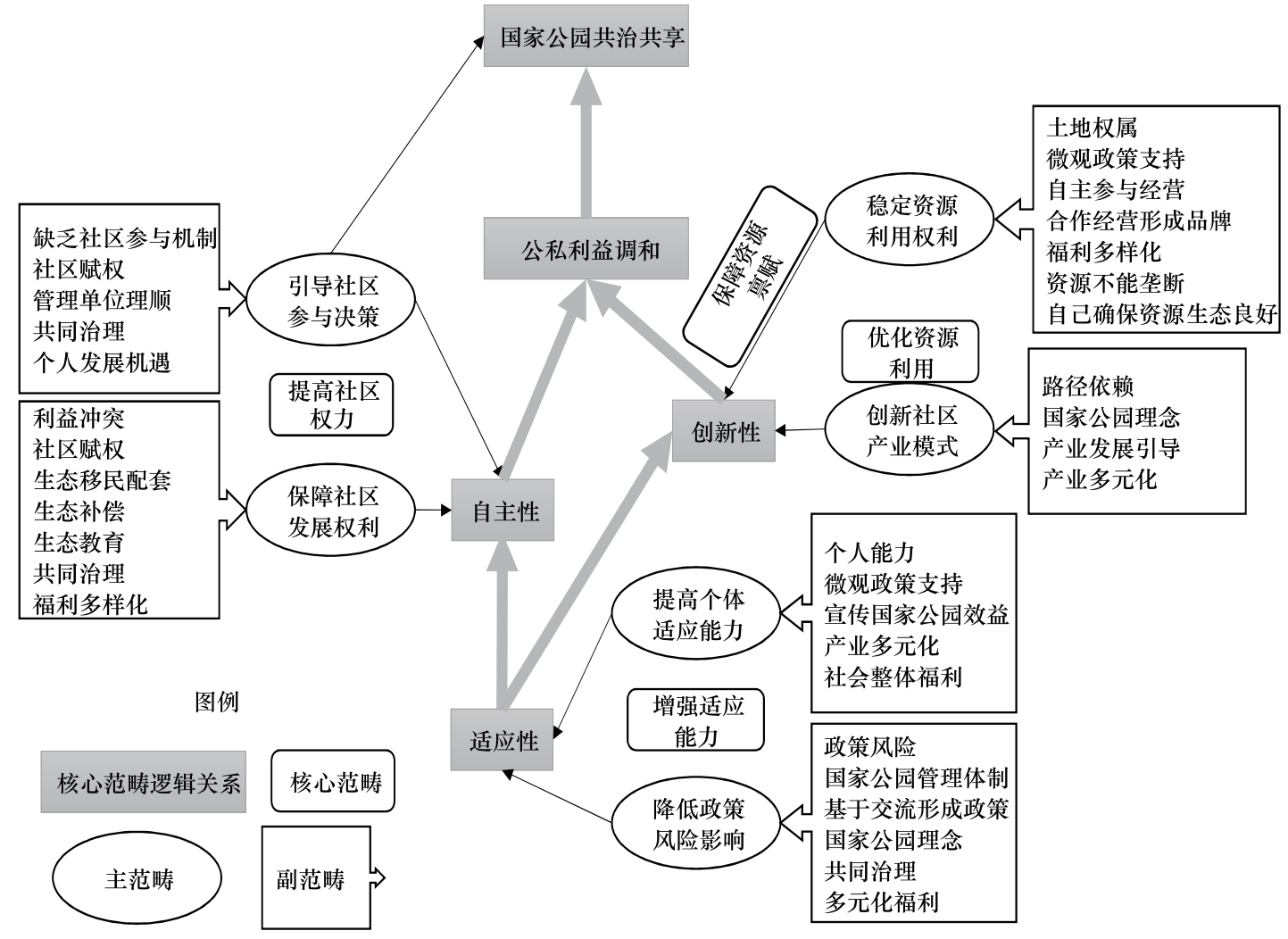

图 3 社区认知-态度-参与国家公园建设的机制模型

Fig.3 Impact analysis model of community participation in National Park designation

首先,社区参与是一个自主性提高的动态过程。武夷山地区在成为国家公园体制试点区之前已经经历了 30 余年的自然保护区、风景名胜区等多种形式自然保护地管理,但从历史经验看并没有形成被社区认可的决 
策参与机制, 当地人普遍认为自己对国家公园建设的信息是被动接受的,对国家公园理念本身并不了解,对其 建设进展也缺乏详细了解, 比照 Pimbert 和 Pretty 根据不同的介人程度划分的 7 类公众参与 ${ }^{[49]}$, 这些认知反 映出社区处于第一、二级的“被动参与”、“信息收集式参与”。“利益冲突”与 “福利多样化” 在反映对国家公 园建设的成本-收益认知外 ${ }^{[33]}$, 也表明第四级的 “物质激励下的参与” 是一种可能,但这仍是一种被动参与。 不过,社区居民认可 “共同治理”, 提出监督国家公园建设、参与生态保护等。社会认同理论表明 ${ }^{[50]}$, 组织身 份能够影响人们的态度和行为, 能够解释群体对待保护地的态度 ${ }^{[51]}$, 这在研究中也得到了体现一一当地人认 为作为依赖水土的本地人要“确保资源生态良好”、“做好地方表率”,这种主人翁意识有利于促进“功能性参 与” “互动性参与”等主动参与。成本-收益认知也反映出, 在多样化的福利诉求中, 人们在个人与家庭经济 收益外,期待国家公园生态效益,这有助于在不同利益相关者之间形成共同利益,减少研究中发现的社区居民 对政策公平性的负面认知引发的相对剥夺感 ${ }^{[52]}$ 。这一沿着参与理论阶梯的不断上升在理论构建中体现为 “社区赋权”过程: 利益相关方的交流有利于提高程序公平 ${ }^{[53]}$ 。自主经营和合作经营带来资源管理权, 从而 促进相关利益群体的自主参与。

其次,社区参与需要首先保障社区生计资源禀赋。环境权利理论指出,环境资源并不绝对稀缺,其可获得 性依赖于制度在不同时空尺度的作用 ${ }^{[54]}$ 。环境权利是人们利用所具有的资源禀赋, 即权力和资源, 来得到各 种生态产品和服务以提升福祉的权利。研究发现, 社区对土地权属现状及其未来变动极为重视, 需要保有林 地的管理权、经营权和收益权。产权理论中的权利束将产权解析为许多权利的构成,如所有权、使用权、收益 权和处置权等; 从权利束中让渡部分权利给自然保护地管理者而保留适当权利被认为是缓解自然保护与社区 土地利用矛盾的合理方式 ${ }^{[55-56]}$ 。前人研究也表明,能否在自然保护地建立后保有对土地/林地的收益权是社 区对自然保护地态度的重要影响因素 ${ }^{[19,57]}$; 本研究中社区对资源垄断的否定态度, 也可以从其他研究中发 现, 即社区认为保护地可能会控制资源 ${ }^{[33,58]}$ 。所以, 这种对土地制度稳定性的诉求, 是对资源禀赋的制度保 障的基本要求, 而自主经营、合作经营与基于土地等自然资源的产业引导则能够促进实现环境权利,避免资源 垄断,实现多样化的福利, 从而激发社区的保护参与自主性。

第三,社区参与需要以实现长期的价值转化为目标。研究表明,武夷山社区居民对现有产业具有一定的 “路径依赖”, 不愿意改变现状并担心现有利益受损, 但同时也追求产业提升带来经济收益。因此, 在国家公 园生态保护理念下, 促进生态价值向经济价值转化成为社区经济发展的必然。这一价值链也是关键的环境权 利 ${ }^{[59]}$, 其建立与巩固需要居民根据自身产业异质性来参与。扎根理论分析发现, 当地人对推崇茶文化、医药 文化和地域文化, 也认可国家公园生态保护功能, 在 “产业多元化” 范畴下,生态旅游成为一个将文化与生态 价值转化为经济价值的重要方式, 将物质供给、文化服务、生态体验等生态产品和服务通过生态理念进行价值 提升。人们也同意建立生态茶园,对这类与保护相兼容的传统产业进行维护或进一步生态化管理,也是社区 参与资源管理的主要途径。这种产业多元化的实现,一方面需要客观上的技术指导和能力提升,另一方面需 要主观上进一步认识到国家公园核心理念及其综合效益, 使社区意识到国家公园管理目标与他们对武夷山生 态环境意义认知的一致性 ${ }^{[46]}$, 尽量消除因保护观念差异而产生的对所谓“他者” 的不信任而更愿意创新产业 模式 ${ }^{[34]}$ 。

最后,社区参与是社会-生态系统适应性治理的趋势。作为自然资源的主要使用者, 自然保护地社区与自 然的互动形成了他们对生态系统意义的认知, 取得了各种生态系统产品和服务, 在影响自然的过程中也发展 了文化,构成了完整的社会-生态系统 ${ }^{[60]}$ 。社会-生态系统适应性治理理论认为,社会-生态系统的复杂性需要 有富有弹性的管理体制来适应变化的自然与社会环境,这一管理体制内化于管理过程, 由多元行动者和多利

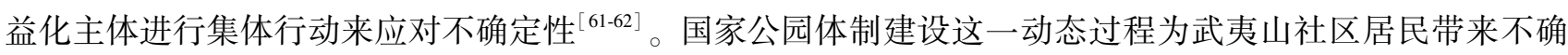
定性,研究表明,一方面人们担忧自身能力不足以应对管理变化, 另一方面对政府决策与政策实施存在不信 任。面对不确定性,社区居民认为需要政策支持提升个人能力来保障经济, 也认为需要完善管理体制和交流 机制来提高社区在国家公园建设与管理中的话语权。不确定性的识别与策略认知反映了社区面对制度环境 
变化的敏锐与主动求变意识,有利于国家公园管理向着适应性治理需要的资源使用者拥有资源使用决策权, 与其他利益主体共同制定使用规则并相互监督 ${ }^{[63-64]}$ 的方式演进。

\section{4 结论与讨论}

\section{1 结论}

本文运用扎根理论,通过深度访谈资料,通过社区对武夷山国家公园的认知,对建立武夷山国家公园的态 度以及对参与武夷山国家公园建设与管理的观点的进行整合分析, 提炼出武夷山国家公园体制试点区社区农 户视角下的国家公园建设与管理的机理模型并予以阐释。研究主要结论如下:

研究表明,自然保护地-社区关系研究提出的“认知-态度-参与”这一行为逻辑在研究区反映为 45 个概念 与 13 个范畴。从编码过程来看,受访者对武夷山国家公园体制建设的态度大多以“我觉得建国家公园好/不 好” 来陈述, 正面认可比负面存疑更为普遍; 态度是非常笼统的陈述, 与对自身利益、建设进展、个人能力等从 认知中提取的丰富概念相关, 也引起对参与行为的多样化陈述, 这也表明认知-态度-参与行为的逻辑是存 在的。

研究提出六个主范畴与四个核心范畴,所构建的社区参与国家公园建设机制模型以调和社区利益与国家 公园公共利益为主线,其核心机制在于,一方面从推进自主性角度不断提升社区参与程度,另一方面从提升创 新性角度巩固资源禀赋与完善环境权利,最终从提升适应性角度,将社区纳人资源管理决策开展多元利益者 适应性治理。这一机理模型的关键在于社区参与能够改变既往自上而下的政策依赖风险,在利益相关者之间 建立信赖关系,在自然保护地管理体制变化中保障社区产业发展, 实现多样化福利, 带来制度变迁中社会-生 态系统的稳定。基于对所发现的 “认知-态度-参与” 的核心观念与所构建的社区参与机理模型, 研究提出从改 善社区认知、提升社区参与角度推进国家公园建设的路径。1) 在进行管理规划时，了解社区居民与其他利益 相关者的共同利益, 在推进国家公园建设中保证信息公开,消除交流障碍, 提高社区居民的被需要感以促进其 参与国家公园建设。2) 在进行产业规划时, 充分考虑社区文化景观的多种价值及其向经济利益的转化潜力, 根据生产者自身特征开展定制化管理与推进产业链合作, 促进横向和纵向利益公平分配, 让社区感知到更多 的参与机会。3)公开规划细节并制定行动计划, 将国家公园建设目标分解成具体项目并持续落实, 以实际成 效建立社区对政策与管理者的信任,通过减少政策风险吸引社区信赖与参与。4) 以负面清单进行土地利用 管理, 明确规则对行为不对人, 尊重社区资源利用传统并充分发挥社区自主管理,提高社区参与国家公园管理 的自觉性。5)将国家公园建设与管理视为动态过程, 利用社区参与的机理模型发展国家公园社区参与状况 评价体系, 分析社区认知、态度与参与的变化、其影响因素及其结果, 促进社区参与的长效机制形成和完善。

\section{2 讨论}

国家公园体制建设本身希望进一步推进社区与保护地的关系,全面提升自然保护管理效率,因此始终试 图推动社区参与其建设与管理。与大部分针对已经建成的自然保护地的社区-保护地关系研究相比, 本研究 的对象是一个处于规划与建设初期的国家公园,其研究结果与既往研究存在相似性,也存在不同。

Wallner 等指出影响居民对生物群区保护区认知的三大类因素包括经济情况、自然保护历史和涉及利益 相关方的权力平衡 ${ }^{[65]}$ 。本研究也表明, 成本-收益衡量是构成社区 “认知-态度-参与” 行为逻辑的主要因素。 从编码统计角度看, 成本主要包含个人能力与生产经营限制; 收益主要涉及发展生态旅游、就业机会、经济收 益。社区也较为关注道路与基础设施和文教等社会公共福利,但没有提及能源使用、人兽冲突等其他常见的 认知影响因素, 说明研究区本身这类问题不明显。此外,与一些研究类似, 国家公园理念宣传缺失 ${ }^{[3,66]}$ 与政策 被动接受 ${ }^{[16,67]}$ 是很多受访者产生中立或消极态度的原因,利益分配与政策执行的公平性 ${ }^{[33]}$ 也是一个关注 要点。

由于宣传缺失, 社区居民大多是表述主观的期待而不是基于国家公园本身功能的客观预期,这与一些研 究有所区别 ${ }^{[34]}$ 。此外, 研究也发现自然保护管理历史经验, 如与以往管理者关系、管理成效等, 几乎没有被提 
及, 只能从大量类似“管理不是老百姓的事情” 的表述中推断社区一直缺乏参与机制。这类历史因素往往被 认为能够影响客观预期 ${ }^{[7,65]}$, 对同一地区的研究也已经发现社区对以往保护历史的认知影响其对新的国家公 园管理体制的期待 ${ }^{[59]}$ 。因此,这一认知缺失可能与社区对国家公园建设的背景不够了解有关, 这种认知偏 差,一定程度上影响了理论构建的完整性。

不过,本研究深人揭示了社区参与国家公园建设的机理,指出以自主性与创新性提升适应性,通过公私利 益协调达到国家公园共治共享。这些研究结果对于追踪武夷山国家公园体制试点进程很有帮助,能够通过提 炼可量化指标,评价与推进社区参与机制。研究形成的参与机制理论,也能够进一步与其他国家公园体制试 点与自然保护地案例研究进行比较。

\section{参考文献 (References) :}

[ 1 ] Holmes C M. The influence of protected area outreach on conservation attitudes and resource use patterns: a case study from western Tanzania. Oryx, 2003, 37(3) : 305-315.

[ 2 ] St. John F A V, Keane A M, Edwards-Jones G, Jones L, Yarnell R W, Jones J P G. Identifying indicators of illegal behaviour: Carnivore killing in human-managed landscapes. Proceedings of the Royal Society B: Biological Sciences, 2012, 279(1729) : 804-812.

[ 3 ] Vodouhê F G, Coulibaly O, Adégbidi A, Sinsin B. Community perception of biodiversity conservation within protected areas in Benin. Forest Policy \& Economics, 2010, 12(7) : 505-512.

[ 4 ] Barzetti V. Parks and Progress: Protected areas and economic development in Latin America and the Caribbean. Washington, DC: IUCN/IDB, 1993: xiii +240 pp.

[ 5 ] Allendorf T, Swe K K, Oo T, Htut Y, Aung M, Allendorf K, Hayek L A, Leimgruber P, Wemmer, C. Community attitudes toward three protected areas in Upper Myanmar (Burma). Environmental Conservation, 2006, 33(4) : 344-352.

[ 6 ] Dewu S, Røskaft, E. Community attitudes towards protected areas: insights from Ghana. Oryx, 2018, 52(3):489-496.

[ 7 ] Ormsby A, Kaplin B A. A framework for understanding community resident perceptions of Masoala National Park, Madagascar. Environmental conservation, 2005, 32(2):156-164.

[ 8 ] Roy A K D. Local community attitudes towards mangrove forest conservation: Lessons from Bangladesh. Marine policy, 2016, 74( DEC.) :186-194.

[ 9 ] Alexander S E. Resident attitudes towards conservation and Black Howler Monkeys in Belize: the Community Baboon Sanctuary. Environmental Conservation, 2000, 27(4):341-350.

[10] Sirivongs K, Tsuchiya T. Relationship between local residents' perceptions, attitudes and participation towards national protected areas: A case study of Phou Khao Khouay National Protected Area, central Lao PDR. Forest Policy \& Economics, 2012, 21: 92-100.

[11] Abdullahi M B. Local communities and sustainable management in Maladumba Lake and Forest Reserve Nigeria. Asian Journal of Biological Sciences, 2012, 5:113-119.

[12] Deng H, Chen Z, Cao H, Shen Y, Wang Y, Shan P. Perceptions and attitudes of local residents on a nature reserve: a case study in Baimaxueshan National Nature Reserve. International Journal of Sustainable Development \& World Ecology, 2015, 22(2) : 165-170.

［13］严圣华, 李兆华, 周振兴. 九宫山自然保护区社区居民对保护区态度调查及协调对策. 林业调查规划, 2007，32(1)：162-167.

[14] 杨佳, 赵清, 杨兴中, 田联会, 何晓军. 太白山自然保护区周边社区群众保护观念和态度取向调查. 林业调查规划, 2007, 32(5): 41-45.

[15］李星群, 文军. 自然保护区周边社区居民对保护区依赖与态度的关系研究. 中南林业调查规划, 2008, 27(3): 45-49.

[16] 熊高明, 申国珍, 㚞大勇, 徐文婷, 周友兵, 赵常明, 谢宗强, WANG Zhi-xian. 湖北神农架自然遗产地社区参与现状及对策. 陕西林业科 技, 2017, 5: 26-31.

[17] 马奔, 冯骥, 陈俐静, 温亚利. 农户对保护区满意度与保护态度分析一一基于中国 7 省保护区周边农户调查. 生态经济, 2017, 33(1)： 146-151.

[18] 程绍文, 张捷, 徐菲菲. 自然旅游地居民自然保护态度的影响因素一一国九寨沟和英国新森林国家公园的比较. 生态学报, 2010, 30 (23) : 6487-6494.

[19] 杨建美, Teri Allendorf, 查国志, 杨力, 何俊波, 班鼎盈. 保护区周边社区对保护区的认知研究一一高黎贡山国家级自然保护区为例. 经济问题探索, 2011, 5: 44-47.

［20］段伟, 温亚利, 王昌海. 朱噮国家级自然保护区农户对环境和朱㟪保护的态度影响因素分析. 湿地科学, 2013, 11(1): 90-99.

[21] 韩锋, 王昌海, 赵正, 任艳梅, 温亚利. 农户对自然保护区综合影响的认知研究——陕西省国家级自然保护区为例. 资源科学, 2015, $37(1): 102-111$.

[22] 吴伟光, 刘强, 刘姿含, 田立斌, 李强. 影响周边社区农户对自然保护区建设态度的主要因素分析. 浙江农林大学学报, 2014, 31(1)： 
97-104.

[23]马奔, 申津羽, 丁慧敏, 温亚利. 基于保护感知视角的保护区农户保护态度与行为研究. 资源科学, 2016, 38(11): 2137-2146.

[24] 李正玲, 陈明勇, 吴兆录, 王倩, 董永华. 西双版纳社区村民对亚洲象保护廊道建设的认知与态度. 应用生态学报, 2009，20(6)： $1483-1487$.

[25] He Q, Wu Z, Zhou, W, Dong R. Perception and Attitudes of Local Communities Towards Wild Elephant-related Problems and Conservation in Xishuangbanna, Southwestern China. Chinese Geographical Science. 2011, 21(5) : 629-636.

[26] Allendorf T D, Yang J M. The role of gender in local residents' relationships with Gaoligongshan Nature Reserve, Yunnan, China. Environment Development \& Sustainability, 2017, 19(1): 185-198.

[27] 王剑, 彭建. 相对剥夺视角下的旅游地社区居民态度研究——以茂兰自然保护区为例. 生态经济(学术版), 2011(2): 34-40+49.

[28] Jim C Y, Xu S S W. Stifled stakeholders and subdued participation: interpreting local responses toward Shimentai Nature Reserve in South China. Environmental Management, 2002, 30(3): 327-341.

[29] Chang L, Watanabe T. The mutual relationship between protected areas and their local residents: The case of Qinling Zhongnanshan UNESCO Global Geopark, China. Environments, 2019, 6(5): 49.

[30]王昭国, 杨兆萍, 曹开军, 安强, 刘群, 王璀蓉. 世界自然遗产保护的社区感知差异及其影响因素分析一一以喀拉峻世界自然遗产地为 例. 干旱区研究, 2016, 33(6): 1311-1317.

[31] Allendorf T D. Residents' attitudes toward three protected areas in southwestern Nepal. Biodiversity and Conservation, 2007, 16(7) : 2087-2102.

[32] Lepp A, Holland S. A Comparison of attitudes toward state-led conservation and community-based conservation in the village of Bigodi, Uganda. Society and Natural Resources, 2006, 19(7): 609-623.

[33] Abukari H, Mwalyosi R B. Comparing conservation attitudes of park-adjacent communities: The case of Mole National Park in Ghana and Tarangire National Park in Tanzania. Tropical Conservation Science, 2018, 11: 1-14.

[34] Nastran M. Why does nobody ask us? Impacts on local perception of a protected area in designation, Slovenia. Land Use Policy, 2015, 46: 38-49.

[35] Seyfi S, Hall C M, Fagnoni E. Managing World Heritage Site stakeholders: a grounded theory paradigm model approach. Journal of heritage tourism, 2019, 14(4): 308-324.

[36] 柴寿升, 龙春风. 旅游社区居民公平感知的影响因素与干预路径——基于扎根理论的一个探索性研究. 旅游论坛, 2019,12(1): 26-34.

[37］李会琴,徐宁. 基于扎根理论的可持续旅游生计策略影响因素研究. 国土资源科技管理, 2018, 35(4)：81-93.

[38] 张曼. 基于扎根理论的少数民族村寨文化认同与旅游扶贫发展路径初探一一湖南省通道县侗族村寨为例. 乐山师范学院学报, 2018, $33(1): 47-51$.

[39] 施玮, 吴赢. 基于扎根理论的生态文化型农村社区再造模式研究. 福州大学学报(哲学社会科学版), 2015, 29(2): 34-41.

[40] 宿丽霞, 郭旭升, 王兆华, 周情. 水源保护区生态补偿机制运行的影响因素一以北京市密云水库为例. 技术经济, 2012, 31(11)： 75-79.

[41] 潘淑兰, 王晓倩, 毛炎, 王坤, 余韵. 社区居民与游客对国家公园的认知与态度分析一一以神农架国家公园为例. 环境保护, 2019, 47 (8) : 65-69.

[42] 夏媛媛, 杨沙, 王子健, 雷泽锋, 田晔, 邹红菲. 东北虎豹国家公园黑龙江片区保护地社区经济与公众认知调查分析. 野生动物学报, $2019,40(2): 395-402$.

[43] Ajzen I, Fishbein M. Understanding Attitudes and Predicting Social Behaviour. New Jersey: Prentice-Hall, 1980.

[44] Glaser B G, Strauss A L. The Discovery of Grounded Theory-Strategies for Qualitative Research. New York: Aldine de Gruyter, 1967.

[45] Strauss A, Corbin J. Basics of Qualitative Research: Grounded Theory Procedures and Techniques. Newbury Park: Sage, 1990.

[46] 何思源, 魏铎, 苏杨, 闵庆文. 保障国家公园体制试点区社区居民利益分享的公平与可持续一一基于社会-生态系统意义认知的研究. 生 态学报, 2020, 40(7):2450-2462.

[47] Strauss A L, Corbin J. Basics of Qualitative Research (2nd ed.). Thousand Oaks, CA: Sage, 1998.

[48] Corbin J, Strauss A. Basics of qualitative research: Techniques and procedures for developing grounded theory (3rd ed.). Thousand Oaks, CA: Sage, 2008.

[49] Pimbert M L, Pretty J N. Parks people and professionals: putting “participation” into protected-area management // Ghimire K B, Pimbert M P, eds. Social Change and Conservation. Environmental Politics and Impacts of National Parks and Protected Areas. London: Earthscan, 1997: 297-330.

[50] Tajfel H. Differentiation between social groups: Studies in the social psychology of intergroup relations. London: Academic Press, 1978.

[51] Stoll-Kleemann S. Barriers to nature conservation in Germany: A model explaining opposition to protected areas. Journal of Environmental Psychology, 2001, 21(4) : 369-385.

[52] Merton R K, Kitt A S. Contributions to the theory of reference group behavior // Merton R K, Lazarsfeld P F, eds. Continuities in social research, 
studies in the scope and method of "The American Soldier”. Glencoe, Ill: The Free Press, 1950: 40-105.

[53] Lind E A, Tyler T R. The Social Psychology of Procedural Justice. US: Springer, 1988. [54] Leach M, Mearns R, Scoones I. Environmental entitlements: dynamics and institutions in community-based natural resource management. World Development, 1999, 27 (2) : 225-247.

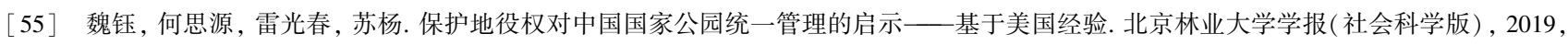
18(1) : 70-79.

[56] 何思源,苏杨,罗慧男,王蕾. 基于细化保护需求的保护地空间管制技术研究一一中国国家公园体制建设为目标. 环境保护,2017,45 (Z1) : 50-57.

[57] Infield M, Namara A. Community attitudes and behaviour towards conservation: an assessment of a community conservation programme around Lake Mburo National Park, Uganda. Oryx, 2001, 35(1): 48-60.

[58] Ite U E. Community perceptions of the Cross River National Park, Nigeria. Environmental Conservation, 1996, 23(4) : 351.

[59］何思源, 苏杨, 王蕾, 程红光. 构建促进保护地社区资源使用与保护目标协调的社会情境分析工具一武夷山国家公园试点区实践. 生 态学报, 2019, 39(11): 3861-3870.

[60] Van Wyk E, Breen C, Freimund W. Meanings and robustness: Propositions for enhancing benefit sharing in social-ecological systems. International Journal of the Commons, 2014, 8 (2): 576-594.

[61] Chaffin B C, Gosnelland H, Cosens, B A. A decade of adaptive governance scholarship: Synthesis and future directions. Ecology and Society, $2014,19(3): 56$.

[62] 宋爽, 王帅, 傅伯杰, 陈海滨, 刘炎序, 赵文武. 社会-生态系统适应性治理研究进展与展望. 地理学报, 2019, 74(11) : 2401-2410.

[63] Ostrom E, Nagendra H. Insights on linking forests, trees, and people from the air, on the ground, and in the laboratory. PNAS, 2007, 103(51): 19224-19231.

[64] 蔡晶晶, 毛寿龙. 复杂“社会-生态系统” 的适应性治理:扩展集体林权制度改革的视野. 农业经济问题, 2011, 32(6): 82-88+112.

[65] Wallner A, Bauer N, Hunziker M. Perceptions and evaluations of biosphere reserves by local residents in Switzerland and Ukraine. Landscape and Urban Planning, 2007, 83(2-3) : 104-114.

[66] Dimitrakopoulos P G, Jones N, Iosifides T, Florokapi I, Lasda O, Paliouras F, Evangelino K I. Local attitudes on protected areas: Evidence from three Natura 2000 wetland sites in Greece. Journal of Environmental Management, 2010, 91(9): 1847-1854.

[67] Haruna Abukari, Paphael Benefict Mwalyosi. Local communities' perceptions about the impact of protected areas on livelihoods and community development. Global Ecology and Conservation, 2020, 22, e00909. 